\title{
Comparing the Effects of White Coat Hypertension and Sustained Hypertension on Mortality in a UK Primary Care Setting
}

\author{
Martin G. Dawes, MBBS, $P b D$ \\ (Lond) ${ }^{1}$ \\ Gillian Bartlett, $\mathrm{PbD}^{1}$ \\ Andrew J. Coats, MBBChir (Camb), \\ $M A, D M^{2}$ \\ Edmund Juszczak, MSc ${ }^{3}$ \\ 'Department of Family Medicine, McGill \\ University, Montreal, Quebec, Canada \\ ${ }^{2}$ Faculty of Medicine, University of Sydney, \\ Sydney, NSW, Australia \\ ${ }^{3}$ Centre for Statistics in Medicine, Univer- \\ sity of Oxford, Oxford, England, United \\ Kingdom
}

\begin{abstract}
PURPOSE We examined all-cause mortality within a primary care setting in patients with white coat hypertension or sustained hypertension in whom blood pressure (BP) monitoring was indicated.

METHODS This prospective multicenter study of ambulatory BP monitoring included 48 family practices in the county of Oxfordshire, United Kingdom. Mortality was compared for patients having white coat hypertension (mean of 3 clinic BP readings $>140 / 90 \mathrm{~mm} \mathrm{Hg}$ and daytime ambulatory readings $\leq 135 / 85$ $\mathrm{mm} \mathrm{Hg}$ ) and patients having sustained hypertension (mean of 3 clinic readings $>140 / 90 \mathrm{~mm} \mathrm{Hg}$ and daytime ambulatory readings $>135 / 85 \mathrm{~mm} \mathrm{Hg}$ ).
\end{abstract}

RESULTS A routine primary care cohort consisting of 5,182 patients chosen to undergo ambulatory BP monitoring by their family physician was followed up for a median of 7.3 years (interquartile range, 5.8-8.9). There were 335 deaths (6.5\%), corresponding to a mortality rate of 8.9 deaths (95\% confidence interval $[\mathrm{Cl}], 8.0-9.9)$ per 1,000 years of follow-up. Patients with white coat hypertension $(n=1,117)$ were more likely to be female and were on average younger than patients with sustained hypertension $(n=4,065)$. The unadjusted rate of all-cause mortality in patients with white coat hypertension was lower, at 4.4 deaths per 1,000 years of follow-up $(95 \% \mathrm{Cl}, 3.1-6.0)$ than that in patients with sustained hypertension, at 10.2 deaths per 1,000 years of follow-up ( $95 \% \mathrm{Cl}, 9.1-11.4)$. This reduction in all-cause mortality was still clinically significant after adjustment for age, sex, smoking, use of antihypertensive medication, and practice-clustering effects (hazard ratio $=0.64 ; 95 \% \mathrm{Cl}, 0.42-0.97 ; P=.04$ ).

CONCLUSIONS White coat hypertension (elevation of clinic BP only) confers significantly less risk of death than sustained hypertension (elevation of both clinic and ambulatory BPs). Trials are now needed to evaluate the risk reduction achievable in patients who have white coat hypertension and are receiving BP-lowering therapy.

Ann Fam Med 2008:6;390-396. DOI: 10.1370/afm.865.

\section{INTRODUCTION}

E levated blood pressure (BP) is common and associated with increased morbidity and mortality. ${ }^{2}$ Although the accurate determination of $\mathrm{BP}$ is therefore of major importance, the currently recommended method of estimating $\mathrm{BP}^{3}$ has several important limitations. Blood pressure varies by time of day ${ }^{4}$ and season. ${ }^{5,6}$ If it is measured only once, or only at 1 time in the day, this reading may give a biased indication of true BP. Other factors contribute to the unreliability of BP measurement as well, including observer bias, such as the dislike of obtaining a reading above a threshold that requires more intervention (ie, recording $88 \mathrm{~mm} \mathrm{Hg}$ instead of $90 \mathrm{~mm} \mathrm{Hg}$ for diastolic pressure), digit preference, ${ }^{7}$ the poor condition of some sphygmomanometers ${ }^{8,9}$ and the rapid loss of proper technique 
after training. ${ }^{6,10}$ This threshold avoidance affects both physicians and nurses in this setting.

Ambulatory BP monitoring has been used for many years in secondary care as a way of assessing patients with elevated $\mathrm{BP}^{11}$ and as a tool in research on antihypertensive agents. ${ }^{12,13}$ Until recently, ambulatory monitoring has been mainly used in the research setting; however, the increasing availability, decreasing cost, and improved reliability of ambulatory BP machines have led to a dramatic increase in their use, ${ }^{14,15}$ including introduction of ambulatory BP monitoring into family practice over the last few years. ${ }^{16-21}$ In addition, such monitoring is now recommended practice for the assessment of BP within some guidelines. ${ }^{22}$

Comparisons between ambulatory BP and BP measured in clinics have shown better reliability for the former, with measures of ambulatory BP better predicting all-cause mortality as well as cardiovascular mortality. ${ }^{23-26}$

A considerable proportion of patients have normal ambulatory BP, but their BP readings are elevated when measured in the office, a phenomenon referred to as white coat hypertension. ${ }^{27,28}$ Its prevalence varies according to both clinic and ambulatory values used as thresholds to define this condition. ${ }^{20,28}$ White coat hypertension has been shown to be associated with less morbidity than hypertension that is sustained outside the clinic; however, no large, long-term followup studies have evaluated its impact on mortality in primary care. ${ }^{29-33}$

The aims of our study were to assess all-cause mortality in patients in whom BP monitoring was indicated and to compare all-cause mortality in patients with BP elevated only in the clinic (white coat hypertension) with that in patients with BP elevated both in the clinic and during ambulatory monitoring (sustained hypertension).

Our main hypothesis was that patients with white coat hypertension would have a significantly lower risk of all-cause mortality compared with patients with sustained hypertension. Secondary hypotheses tested in this study were the effects of sex, age, smoking, and use of antihypertensive medication at the time of monitoring on the risk associated with white coat hypertension. In addition, we investigated the same associations for cardiovascular mortality.

\section{METHODS}

\section{Study Design}

This study was based on prospective multipractice data from patients within a multicohort study that has been described previously. ${ }^{23}$

Patient smoking status, current use of antihyperten- sive medication at the time of ambulatory BP monitoring, and sex were recorded by the office nurse at the time that patients were provided with the monitor. Personal identification data, including date of birth and the national health insurance number, were also collected and sent to the Office of National Statistics, which linked patient records with the death registry and provided the date of death. The primary outcome for our study was all-cause mortality. Cause of death or contributing cause of death was also identified from the death registry and classified as cardiovascular or noncardiovascular using codes from the International Classification of Diseases 9th Revision (ICD-9).

Patient data were collected from January 1, 1992, to February 28, 1997. Data from the death registry were obtained up until September 2003. Ethics approval for this study was granted by the Central Oxfordshire Research Ethics Committee of the Oxfordshire Health Authority.

\section{Study Population}

In 1992, the regional (Oxfordshire) health authority provided ambulatory BP monitors (TM-2420 monitors, version 7; A\&D Engineering, Milpitas, California) to 52 family physician practices. Oxfordshire is an affluent county in southeast England with a mixture of rural regions and small cities, and a population of 631,900 (in 2006) in a land area of 2,605 $\mathrm{km}^{2}$. Most study practices were semirural and urban, covering mainly white populations in nondeprived areas. We invited all of the family physicians to provide data for the current study, and 48 (92\%) agreed.

We retrieved data for 6,953 patients who had been selected for ambulatory BP monitoring based on the clinical judgment of their participating physicians. Physicians' main reasons for initiating monitoring in the study patients were a variable clinic BP (35.9\%), a borderline clinic BP (35.4\%), established hypertension resistant to treatment $(8.4 \%)$, and isolated high clinic BP (7.6\%). The most common diagnostic hypertensive category for these patients (42.3\%) was newly diagnosed hypertension with initiation of ambulatory monitoring before starting any treatment.

From this cohort, 1,771 patients were excluded. Forty-five patients did not have available mortality data, 22 were missing ambulatory readings, 783 had invalid ambulatory readings, and 596 had fewer than 3 clinic readings in the previous 6 months. There was no record of medication status in 515 patients and no record of smoking in 218. This process left a cohort of 5,182 patients. There was no difference in the available data for sex, age, clinic BP, ambulatory BP, smoking status, or antihypertensive medication use between patients included in and excluded from further analysis. 


\section{BP Measurement}

Clinic BP was defined as the mean of the 3 most recent readings in the clinic during the previous 6 months, recorded using normal office techniques and equipment, before the patients underwent ambulatory BP monitoring.

Ambulatory BP was measured using monitors previously validated according to guidelines of the Association for the Advancement of Medical Instrumentation. ${ }^{34-36}$ All ambulatory recordings were assessed for inclusion in the analyses. Monitoring was done over a 24-hour period; BP was measured every half hour during the day (7 AM to $11 \mathrm{PM}$ ) and every hour during the night. All results were available to the family physicians. An ambulatory recording was defined as invalid if fewer than 20 valid daytime ambulatory measurements were obtained or if more than $15 \%$ of the readings were invalid (an error recorded by the monitor).

Of note, in contrast to the situation in some other settings, the nurses in this study were routinely involved in screening and management of hypertension and so were aware of the levels for BP management, which may have reduced the likelihood of threshold avoidance. As part of this study, nurses were encouraged to attend the research study update meetings where hypertension guidelines were routinely discussed.

\section{Classification of Patients}

On the basis of concordance of the clinic BP reading and the daytime (7 AM to $11 \mathrm{PM}$ ) ambulatory BP recordings, patients were grouped into 1 of 2 categories determined from current hypertension guidelines ${ }^{37}$ : (1) white coat hypertension (defined as a clinic systolic BP $>140 \mathrm{~mm} \mathrm{Hg}$ and daytime ambulatory systolic $\leq 135 \mathrm{~mm} \mathrm{Hg}$, and/or clinic diastolic BP >90 mm $\mathrm{Hg}$ and daytime ambulatory diastolic BP $\leq 85 \mathrm{~mm} \mathrm{Hg}$ ) or (2) sustained hypertension (defined as clinic systolic $\mathrm{BP}>140 \mathrm{~mm} \mathrm{Hg}$ and daytime ambulatory systolic BP $>135 \mathrm{~mm} \mathrm{Hg}$, and/or clinic diastolic BP >90 mm Hg and daytime ambulatory diastolic BP >85 $\mathrm{mm} \mathrm{Hg}$ ).

In all, 1,117 patients had white coat hypertension and 4,065 patients had sustained hypertension.

\section{Statistical Analysis}

We performed data entry and validation using DBase IV software (dataBased Intelligence Inc, Vestal, New York). Analysis was performed using version 11.0 of SPSS for Windows (SPSS Inc, Chicago, Illinois) and version 9.2 of Stata (Stata Corp, College Station, Texas). Patient characteristics and BP measures were summarized using frequencies (percentages) for binary variables, means with standard deviations (SDs) for normally distributed continuous variables, or medians with range or interquartile range (IQR) for nonnormally distributed continuous variables. We compared these characteristics using the $\chi^{2}$ test for binary variables and the independent 2 -sample $t$ test for normally distributed continuous variables. To assess the potential effect of clustering by practice on outcome, the intraclass correlation coefficient (ICC) was calculated. Multivariate survival analysis was performed using the Cox regression model to evaluate the risk of mortality associated with white coat hypertension compared with sustained hypertension, adjusting for important prognostic factors including sex, age, smoking history, and prescribed antihypertensive medication recorded at the time of monitoring, and also for clustering at the practice level.

\section{RESULTS}

\section{Characteristics of the Study Cohort}

Of the 5,182 patients, 1,299 (25.1\%) were current smokers and 1,161 (22.4\%) were exsmokers. At the time of ambulatory monitoring, 1,675 patients $(32.3 \%)$ were taking antihypertensive medication. The patients had a mean age of 56.9 years $(\mathrm{SD}, 12.5)$ and 2,336 (45.1\%) were male.

There were statistically significant and clinically important differences in these risk factors between the patients with white coat hypertension and the patients with sustained hypertension (Table 1). The former patients were more likely to be female, were on average younger, and were less likely to be smokers, all of which would reduce their risk of mortality. They were also marginally more likely than their counterparts with sustained hypertension to already be taking antihypertensive medication when monitoring began, although this difference was neither clinically nor conventionally statistically significant.

Compared with patients with white coat hypertension, patients with sustained hypertension had significantly higher clinic $\mathrm{BPs}_{\text {; }}$ the mean difference in systolic 


\begin{tabular}{|c|c|c|c|}
\hline Measure & $\begin{array}{l}\text { White Coat } \\
\text { Hypertension } \\
\text { (n=1,117) }\end{array}$ & $\begin{array}{c}\text { Sustained } \\
\text { Hypertension } \\
(n=4,065)\end{array}$ & $\begin{array}{c}\text { Mean Difference } \\
(95 \% \mathrm{Cl}) \\
{[P \text { Value }]}\end{array}$ \\
\hline \multicolumn{4}{|l|}{$\begin{array}{l}\text { Systolic blood pressure, } \\
\mathrm{mm} \mathrm{Hg}\end{array}$} \\
\hline Clinic & $159.5(13.1)$ & $168.8(15.6)$ & $9.2(8.2-10.2)[<.001]$ \\
\hline Ambulatory & $126.9(6.8)$ & $156.3(14.9)$ & $29.4(28.5-30.3)[<.001]$ \\
\hline Clinic minus ambulatory & $32.6(14.5)$ & $12.4(16.7)$ & - \\
\hline \multicolumn{4}{|l|}{$\begin{array}{l}\text { Diastolic blood pressure, } \\
\mathrm{mm} \mathrm{Hg}\end{array}$} \\
\hline Clinic & $94.5(7.5)$ & $96.6(8.3)$ & $2.1(1.6-2.7)[<.001]$ \\
\hline Ambulatory & $83.2(8.0)$ & $92.3(10.2)$ & $9.2(8.5-9.8)[<.001]$ \\
\hline Clinic minus ambulatory & $11.3(8.9)$ & $4.3(9.5)$ & - \\
\hline
\end{tabular}

$\mathrm{Cl}=$ confidence interval.

Note: Values are expressed as mean (SD) or mean difference (SD).

\begin{tabular}{|c|c|c|}
\hline Characteristic & $\begin{array}{l}\text { White Coat } \\
\text { Hypertension } \\
(n=1,117)\end{array}$ & $\begin{array}{c}\text { Sustained } \\
\text { Hypertension } \\
(n=4,065)\end{array}$ \\
\hline Total population & $4.4(3.1-6.0)$ & $10.2(9.1-11.4)$ \\
\hline \multicolumn{3}{|l|}{ Sex } \\
\hline Male & $5.0(2.9-8.6)$ & $11.8(10.2-13.8)$ \\
\hline Female & $4.1(2.7-6.1)$ & $8.6(7.3-10.2)$ \\
\hline \multicolumn{3}{|l|}{$\begin{array}{l}\text { Antihypertensive } \\
\text { medication }\end{array}$} \\
\hline Yes & $6.3(3.9-9.9)$ & $16.3(13.9-19.2)$ \\
\hline No & $3.3(2.1-5.3)$ & $7.4(6.3-8.7)$ \\
\hline \multicolumn{3}{|l|}{ Smoking status } \\
\hline Nonsmoker & $2.9(1.7-4.9)$ & $9.3(7.9-10.9)$ \\
\hline $\begin{array}{l}\text { Smoker or } \\
\text { exsmoker }\end{array}$ & $6.5(4.3-9.8)$ & $11.2(9.6-13.2)$ \\
\hline \multicolumn{3}{|l|}{ Age-group, years } \\
\hline$<50$ & $0.9(0.3-2.9)$ & $1.9(1.2-3.2)$ \\
\hline $50-59$ & $3.3(1.6-6.6)$ & $4.1(3.0-5.7)$ \\
\hline $60-69$ & $7.7(4.6-12.8)$ & $14.0(11.6-16.8)$ \\
\hline$\geq 70$ & $14.9(8.0-27.8)$ & $29.4(24.8-34.8)$ \\
\hline
\end{tabular}

values was $9.2 \mathrm{~mm} \mathrm{Hg}$ (95\% confidence interval [CI], $8.2-10.2)$, and the mean difference in diastolic values was $2.1 \mathrm{~mm} \mathrm{Hg}$ (95\% CI, 1.6-2.7) (Table 2). Patients with sustained hypertension also had significantly higher ambulatory $\mathrm{BPs}_{\text {; }}$ the mean difference in systolic values was $29.4 \mathrm{~mm} \mathrm{Hg}$ (95\% CI, 28.5-30.3), and the mean difference in diastolic values was $9.2 \mathrm{~mm} \mathrm{Hg}$ (95\% CI, 8.5-9.8). These differences, in addition to the factors outlined above, were likely to lead to higher mortality in the sustained hypertension group.

Analysis of the effect of clustering showed a small ICC of 0.0068 for all-cause mortality. The ICC for cardiovascular mortality was 0.00072 .

\section{Mortality}

The mean length of follow-up for the patients overall was 7.3 years (SD, 2.0), and the median length of follow-up was 7.3 years (IQR, 5.8-8.9). Patients with white coat hypertension were followed up for a mean of 7.4 years (SD, 1.9), and those with sustained hypertension were followed up for a mean of 7.2 years (SD, 2.0).

Some $36(3.2 \%)$ of the patients with white coat hypertension and 299 (7.4\%) of the patients with sustained hypertension died. When patients were categorized by clinic and ambulatory systolic BP quartiles, the number of deaths was greatest in the patients with higher clinic $\mathrm{BP}_{\text {; }}$ in addition, within that group, the number increased significantly with increasing ambulatory BP.

The overall mortality rate was 8.9 deaths per 1,000 years of patient follow-up (95\% CI, 8.0-9.9). Crude rates of all-cause mortality were significantly lower in patients with white coat hypertension, at 4.4 deaths (95\% CI, 3.1-6.0) per 1,000 years, compared with patients with sustained hypertension, at 10.2 deaths (95\% CI, 9.1-11.4) per 1,000 years $(P<.001)$ (Table 3$)$.

Crude all-cause mortality rates were also lower overall in female patients and patients who had never smoked, and they increased with age (Table 3). Patients who were already taking medication at the initiation of BP monitoring had a higher mortality rate. Compared with their counterparts not taking medication, these patients tended to be older (mean age, 61.6 vs 54.6 years) and had a higher clinic BP (5.1 mm Hg higher, $P<.001)$; however, ambulatory BP and sex breakdown did not differ by medication status.

In $18(50.0 \%)$ of the 36 patients with white coat hypertension who died and 151 (50.5\%) of the 299 patients with sustained hypertension who died, death was due to cardiovascular causes. The crude rate of cardiovascular mortality per 1,000 years of patient follow-up was significantly lower in patients with white coat hypertension, at 2.2 deaths (95\% CI, 1.4-3.5), than in patients with sustained hypertension, at 5.3 deaths $(95 \% \mathrm{CI}, 4.5-6.2)(P<.01)$.

The risk of all-cause mortality of patients with white coat hypertension was clinically and statistically significantly lower than that of patients with sustained hypertension, after adjusting for the independent risk factors of age, sex, smoking status, and antihypertensive medication use, and for clustering (hazard ratio, 0.64 ; 


\begin{tabular}{|c|c|c|c|c|c|c|}
\hline \multirow[b]{2}{*}{ Characteristic } & \multicolumn{3}{|c|}{$\begin{array}{l}\text { All-Cause Mortality } \\
\text { ( } \mathrm{n}=355 \text { Deaths) }\end{array}$} & \multicolumn{3}{|c|}{$\begin{array}{l}\text { Cardiovascular Mortality } \\
\text { ( } \mathrm{n}=169 \text { Deaths) }\end{array}$} \\
\hline & HR & $95 \% \mathrm{Cl}$ & $\begin{array}{c}P \\
\text { Value }\end{array}$ & HR & $95 \% \mathrm{Cl}$ & $\begin{array}{c}P \\
\text { Value }\end{array}$ \\
\hline \multicolumn{7}{|l|}{ White coat hypertension } \\
\hline Crude ${ }^{a}$ & 0.43 & $0.30-0.60$ & $<.001$ & 0.43 & $0.29-0.63$ & $<.001$ \\
\hline Adjusted $^{b}$ & 0.64 & $0.42-0.97$ & .04 & 0.63 & $0.39-1.02$ & .058 \\
\hline Male sex ${ }^{b}$ & 1.66 & $1.34-2.06$ & $<.001$ & 1.95 & $1.47-2.59$ & $<.001$ \\
\hline Age (5-year increments) ${ }^{b}$ & 1.61 & $1.52-1.71$ & $<.001$ & 1.63 & $1.50-1.77$ & $<.001$ \\
\hline Smoker or exsmoker ${ }^{b}$ & 1.39 & $1.16-1.67$ & $<.001$ & 1.25 & $0.95-1.64$ & .12 \\
\hline $\begin{array}{l}\text { Not taking antihypertensive } \\
\text { medication }^{\mathrm{b}}\end{array}$ & 0.75 & $0.61-0.93$ & .008 & 0.72 & $0.56-0.94$ & .01 \\
\hline \multicolumn{7}{|c|}{$\mathrm{HR}=$ hazard ratio; $\mathrm{Cl}=$ confidence interval. } \\
\hline \multicolumn{7}{|c|}{$\begin{array}{l}\text { a Crude/unadjusted hazard ratio (estimated using univariate Cox regression model) for white coat hypertension } \\
\text { vs sustained hypertension. }\end{array}$} \\
\hline \multicolumn{7}{|c|}{$\begin{array}{l}{ }^{b} \text { Adjusted hazard ratios (estimated using multivariate Cox regression model). Values were adjusted for blood } \\
\text { pressure category, sex, age (continuous), smoking, antihypertensive medication use, and clustering at the } \\
\text { practice level. Reference groups were as follows: blood pressure category: sustained hypertension; sex: female; } \\
\text { smoking: never smokers; and antihypertensive medication use: taking medication. }\end{array}$} \\
\hline
\end{tabular}

to monitor patients' BP using an ambulatory monitor. The high percentage of technically satisfactory recordings we obtained was largely due to the expertise of the practice nurses who were responsible for attaching the monitor to patients and instructing patients in its use.

Many studies have shown that $\mathrm{BP}$ readings measured using ambulatory monitors are lower than clinic readings ${ }^{41}$ and that the risk of death associated with ambulatory BP is lower than that associated with clinic $\mathrm{BP}^{23}$; however, the precise levels of ambulatory BP that should be considered equivalent to recognized cutoffs for clinic BP in terms of risk or benefit from anti-
95\% CI, 0.42-0.97; $P=.04$ ) (Table 4). This difference corresponds to an estimated $36 \%$ lower risk of death, adjusting for important covariates. In addition, patients with white coat hypertension had a similar estimated $37 \%$ lower risk of cardiovascular mortality relative to their counterparts with sustained hypertension.

\section{DISCUSSION}

White coat hypertension has been shown to be associated with an increased risk of cardiovascular mortality and morbidity as well as all-cause mortality. ${ }^{29-31,38-40}$ Very little work has explored the prognostic significance of the white coat effect in primary care, however. ${ }^{32}$ Our study is the first large, long-term follow-up study to compare the mortality risk of white coat hypertension with that of sustained hypertension in this setting. Our finding of a significantly lower risk of death with the former is similar to that seen in a recent meta-analysis of 4 studies performed in secondary care. ${ }^{40}$ This finding stands in contrast, however, to that of other research showing a similar mortality rate in patients with white coat hypertension and sustained hypertension, although that research was conducted in a much smaller population. ${ }^{30}$ Different methods of recruitment and different populations across studies, as well as variation in findings, have left a considerable level of uncertainty about the exact risk associated with white coat hypertension. ${ }^{40}$

Ambulatory BP recording in primary care has recently been recommended as a method of assessing $\mathrm{BP}$ in patients thought to be hypertensive. ${ }^{37}$ Our study shows that it is possible within routine primary care hypertensive treatment remain uncertain. Clear epidemiologic evidence shows that the treatment of mild to moderate hypertension detected in the clinic reduces cardiovascular endpoints by as much as $50 \%$ but has less effect on all-cause mortality. ${ }^{42,43}$

There are limitations to this study. We undertook a pragmatic longitudinal study carried out in normal practice settings. Patients were selected opportunistically by the physicians and as such may not have represented the total population of patients within these practices. Finally, some important predictors of mortality, such as cholesterol, were not available in this analysis because of the nature of the study.

The implication of this research for family medicine is that we need to consider evaluating patients in greater depth before starting treatment for hypertension. Currently, the guidelines recommend an evaluation of global cardiovascular risk to guide treatment recommendations. We need to now reconsider whether to stop using office BP as both the routine screening test and the diagnostic test for hypertension.

Subsequent controlled clinical trials in primary care would be needed to test the benefits of interventions at different thresholds of ambulatory BP. These studies are now indicated.

To read or post commentaries in response to this article, see it online at http://www.annfammed.org/cgi/content/full/6/5/390.

Key words: Hypertension; white coat; mortality; primary care; family practice; ambulatory monitoring; blood pressure; practice-based research

Submitted August 24, 2007; submitted, revised, March 10, 2008; accepted March 13, 2008. 
A previous version of this paper was presented at the Annual Meeting of the North American Primary Care Research Group; Orlando, Florida; October 10-13, 2004

Funding support: This research was supported by funding from a UK National Health Service Research \& Development grant and from the CVD \& Stroke Programme.

Acknowledgments: We extend our appreciation to the Oxford Ambulatory Blood Pressure Monitoring (OXAM) Study Committee (Professor J. Bell, Dr S. J. Clark, Dr A. Coats, Dr J. Conway, Dr M. G. Dawes, Dr D. Ebbs, Dr G. Fowler, A. Fuller, Professor J. Ledingham, and Professor P. Sleight) and to the 48 primary care practices and their nurses.

\section{References}

1. Qureshi Al, Suri MF, Kirmani JF, Divani AA. Prevalence and trends of prehypertension and hypertension in United States: National Health and Nutrition Examination Surveys 1976 to 2000. Med Sci Monit. 2005;11(9):CR403-CR409.

2. Lewington S, Clarke R, Qizilbash N, Peto R, Collins R; Prospective Studies Collaboration. Age-specific relevance of usual blood pressure to vascular mortality: a meta-analysis of individual data for one million adults in 61 prospective studies. Lancet. 2002;360(9349):1903-1913.

3. 1999 World Health Organization-International Society of Hypertension Guidelines for the Management of Hypertension. Guidelines Subcommittee. J Hypertens. 1999;17(2):151-183.

4. Van Dongen HP, Maislin G, Kerkhof GA. Repeated assessment of the endogenous 24-hour profile of blood pressure under constant routine. Chronobiol Int. 2001;18(1):85-98

5. Brennan PJ, Greenberg G, Miall WE, Thompson SG. Seasonal variation in arterial blood pressure. Br Med J (Clin Res Ed). 1982;285(6346):919-923.

6. Kay LE. Accuracy of blood pressure measurement in the family practice center. J Am Board Fam Pract. 1998;11(4):252-258.

7. Hessel PA. Terminal digit preference in blood pressure measurements: effects on epidemiological associations. Int J Epidemiol. 1986;15(1):122-125

8. McCartney P, Crawford D. Inaccurate, leaky sphygmomanometers are still common. Br J Gen Pract. 2003;53(486):61-62

9. Knight $T$, Leech $F$, Jones $A$, et al. Sphygmomanometers in use in general practice: an overlooked aspect of quality in patient care. J Hum Hypertens. 2001;15(10):681-684.

10. Bailey $\mathrm{RH}$, Bauer $\mathrm{JH}$. A review of common errors in the indirect measurement of blood pressure. Sphygmomanometry. Arch Intern Med. 1993;153(24):2741-2748.

11. Weber MA. Evaluating the diagnosis and prognosis of hypertension by automated blood pressure monitoring: outline of a symposium. Am Heart J. 1988;116(4):1118-1123.

12. Coats AJ, Conway J, Somers VK, Isea JE, Sleight P. Ambulatory pressure monitoring in the assessment of antihypertensive therapy. Cardiovasc Drugs Ther. 1989;1(Suppl 1):303-311.

13. Conway J, Coats A. Value of ambulatory blood pressure monitoring in clinical pharmacology. J Hypertens Suppl. 1989;7(3):S29-S32.

14. Shapiro AP, Karschner JK, Glunk DJ, Barnhill BM. Clinical use of ambulatory blood pressure monitoring. A review of value in patient care. Arch Fam Med. 1995;4(8):691-696.

15. Staessen JA, Fagard R, Lijnen P, et al. Ambulatory blood pressure and blood pressure measured at home: progress report on a population study. J Cardiovasc Pharmacol. 1994;23(5):S5-S11.

16. Prasad N, Isles C. Ambulatory blood pressure monitoring: a guide for general practitioners. BMJ. 1996;313(7071):1535-1541.
17. Taylor RS, Stockman J, Kernick D, Reinhold D, Shore AC, Tooke JE. Ambulatory blood pressure monitoring for hypertension in general practice. J R Soc Med. 1998;91(6):301-304.

18. Martinez MA, García-Puig J, Martín JC, et al. Frequency and determinants of white coat hypertension in mild to moderate hypertension: a primary care-based study. Monitorizacion Ambulatoria de la Presion Arterial (MAPA)-Area 5 Working Group. Am J Hypertens. 1999;12(3):251-259.

19. Pannarale G, Gaudio C, Cristina Acconcia M, Cuturello D. Results of antihypertensive treatment by primary and secondary care physicians as assessed by ambulatory blood pressure monitoring. Blood Press Monit. 2000;5(4):223-226.

20. Rugnath T, Pillay BJ, Cassimjee MH. Twenty-four hour ambulatory blood pressure monitoring in general practice. S Afr Med J. 2000;90(9):898-904

21. Gardner SF, Schneider EF. 24-Hour ambulatory blood pressure monitoring in primary care. J Am Board Fam Pract. 2001;14(3):166-171.

22. Myers MG, Tobe SW, McKay DW, et al. New algorithm for the diagnosis of hypertension. Am J Hypertens. 2005;18(10):1369-1374.

23. Dawes MG, Coats AJ, Juszczak E. Daytime ambulatory systolic blood pressure is more effective at predicting mortality than clinic blood pressure. Blood Press Monit. 2006;11(3):111-118.

24. Verdecchia P, Reboldi G, Porcellati C, et al. Risk of cardiovascular disease in relation to achieved office and ambulatory blood pressure control in treated hypertensive subjects. J Am Coll Cardiol. 2002;39(5):878-885

25. Ohkubo T, Imai Y, Tsuji I, et al. Prediction of mortality by ambulatory blood pressure monitoring versus screening blood pressure measurements: a pilot study in Ohasama. J Hypertens. 1997;15(4):357-364.

26. Perloff $D$, Sokolow M, Cowan R. The prognostic value of ambulatory blood pressures. JAMA. 1983;249(20):2792-2798.

27. Pickering TG, James GD, Boddie C, Harshfield GA, Blank S, Laragh JH. How common is white coat hypertension? JAMA 1988;259(2):225-228.

28. Hoegholm A, Kristensen KS, Madsen NH, Svendsen TL. White coat hypertension diagnosed by 24-h ambulatory monitoring. Examination of 159 newly diagnosed hypertensive patients. Am J Hypertens. 1992;5(2):64-70.

29. Verdecchia P, Porcellati C. Defining normal ambulatory blood pressure in relation to target organ damage and prognosis. Am J Hypertens. 1993;6(Pt 2):2075-210S

30. Gustavsen PH, Høegholm A, Bang LE, Kristensen KS. White coat hypertension is a cardiovascular risk factor: a 10 year follow up study. J Hum Hypertens. 2003;17(12):811-817.

31. Strandberg TE, Salomaa V. White coat effect, blood pressure and mortality in men: prospective cohort study. Eur Heart J. 2000;21(20):1714-1718.

32. Fagard RH, Van Den Broeke C, De Cort P. Prognostic significance of blood pressure measured in the office, at home and during ambulatory monitoring in older patients in general practice. J Hum Hypertens. 2005;19(10):801-807.

33. Sega R, Facchetti R, Bombelli M, et al. Prognostic value of ambulatory and home blood pressures compared with office blood pressure in the general population: follow-up results from the Pressioni Arteriose Monitorate e Loro Associazioni (PAMELA) study. Circulation. 2005;111(14):1777-1783.

34. Clark S, Hofmeyr GJ, Coats AJ, Redman CW. Ambulatory blood pressure monitoring during pregnancy: validation study of the TM2420 monitor. Obstet Gynecol. 1991;77(1):152-155.

35. White WB, Pickering TG, Morganroth J, et al. A multicenter evaluation of the AED TM-2420 ambulatory blood pressure recorder. Am J Hypertens. 1991;4(11):890-896. 
36. Kelly JJ, Hunyor SN, Ho KY. Evaluation of the reproducibility and accuracy of ambulatory blood pressure monitoring using the Takeda TM-2420 automated blood pressure monitor. Clin Exp Hypertens. 1993;15(2):271-287.

37. Hemmelgarn BR, McAlister FA, Grover S, et al. The 2006 Canadian Hypertension Education Program recommendations for the management of hypertension: Part I-Blood pressure measurement, diagnosis and assessment of risk. Can J Cardiol. 2006;22(7):573-581.

38. Verdecchia P, Porcellati C, Schillaci G, et al. Ambulatory blood pressure. An independent predictor of prognosis in essential hypertension. Hypertension. 1994;24(6):793-801.

39. Ohkubo T, Kikuya M, Metoki H, et al. Prognosis of "masked" hypertension and "white-coat" hypertension detected by 24-h ambulatory blood pressure monitoring 10-year follow-up from the Ohasama study. J Am Coll Cardiol. 2005;46(3):508-515.
40. Hansen TW, Kikuya M, Thijs L, et al. Prognostic superiority of daytime ambulatory over conventional blood pressure in four populations: a meta-analysis of 7,030 individuals. J Hypertens. 2007;25(8):1554-1564

41. Pickering TG, Harshfield GA, Devereux RB, Laragh JH. What is the role of ambulatory blood pressure monitoring in the management of hypertensive patients? Hypertension. 1985;7(2):171-177.

42. MRC trial of mild hypertension: principal results. Medical Research Council Working Party. Br Med J (Clin Res Ed). 1985;291(6488):97-104.

43. Collins R, Peto R, MacMahon S, et al. Blood pressure, stroke, and coronary heart disease. Part 2, short-term reductions in blood pressure: overview of randomised drug trials in their epidemiological context [review; see comments]. Lancet. 1990;335(8693):827-838.

\section{CHANGE-OF-ADDRESS FORM FAMIIYY MEDICINE}

Please complete this form and mail to the following address or fax to Annals Circulation at 913-906-6080:

Annals of Family Medicine, Circulation Department, 11400 Tomahawk Creek Pkwy, Leawood, KS 66211-2680

Check if member of sponsoring organization:

\section{$\square$ AAFP $\square$ ABFM $\square$ STFM $\square$ ADFM \\ $\square$ AFMRD $\square$ NAPCRG $\square$ CFPC}

ID number from label on your journal cover

OLD Information (Please print.)

Name

Company (if applicable)

Address (Street plus Apt or Ste)

\begin{tabular}{lc}
\hline City & State \\
\hline Country & Postal Code (9-digit ZIP for US)
\end{tabular}

Telephone

Fax
NEW Information (Please print.)

\begin{tabular}{ll}
\hline Name & \\
\hline Company (if applicable) & \\
\hline Address (Street plus Apt or Ste) & State \\
\hline City & Postal Code (9-digit ZIP for US) \\
\hline Country & Fax \\
\hline Telephone & \\
\hline E-Mail &
\end{tabular}

